\title{
Identify the limit states of Hashazini dam by applying Incremental dynamic analysis
}

\author{
Ali Majdi', Alaa Jabbar Rahman ${ }^{2}$ \\ ${ }^{1}$ Al-Mustaqbal University College \\ Al-Najaf Street, Hilla, Iraq \\ alimajdi@mustaqbal-college.ed.iq \\ ${ }^{2}$ Technical University of Civil Engineering of Bucharest \\ Bucharest, Romania \\ alaajabbar2017@gmail.com
}

\begin{abstract}
The aim of this paper is to develop the Incremental dynamic analysis (IDA) for existing gravity dam (Hashazini dam) which located in the north of Iraq. The incremental dynamic analysis (IDA) is presented in this paper in order to determine the limit states and capacity of a gravity dam. In order to achieve this target, a series of ground motions are applied to a dam immediately one after other with increasing the intensity levels, that leads to change the behaviour of the dam from elastic situation to inelastic one and lastly causes collapse. In this paper seven ground motions considered as input data for nonlinear analysis, these records are depend on real earthquake worldwide. For the analysis purpose, the Hashazini dam has been chosen as a case study with developing of IDA curves and identifying performance level in case of single ground motion and for repeated ground motions. Incremental dynamic analyses (IDA) were performed for those simulated dams using seven artificial ground motions with scaling peak ground acceleration (PGA) increased by a $0.3 \mathrm{~g}$ until it achieved $2.2 \mathrm{~g}$ to determine the drift capacity of the dam in Service state limit SLS and ultimate state limit ULS. However, this paper was used ANSYS simulation to investigate the effect of earthquake shaking on the Hashazini dam and the weakness of the dam body.
\end{abstract}

Keywords: Earthquake, Incremental dynamic analysis (IDA), Hashazini dam, Sulaymaniyah.

\section{Introduction}

Iraq as a country has $438320 \mathrm{~km}^{2}$ as an overall area, it is bordered by six countries from all directions in addition to Arab Gulf as a natural border in the southeast. Turkey, Iran to the north and the east respectively; Saudi Arabia and Kuwait to the south and southwest, while Jordan and Syria to the west and northwest respectively. Iraqi topographic is shaped as a basin be formed of the Great Mesopotamian silty plain of the Euphrates and Tigris rivers which literally means the land that located between two rivers (Mesopotamia). The silty plain surrounded in the east and north by mountains in different heights, and the desert is surrounded it in the west and south parts [1].

In the last few years, the Iraqi regions were suffering from a series of earthquake shaking, and especially in the north-east parts of Iraq near to Iran bonder due to oblique-thrust faulting at mid-crustal depth ( $25 \mathrm{~km})$. In 2017, Halabjah city which located in Sulaymaniyah governorate was hit by an earthquake with magnitude M 7.3 as shown in Figure 1. The main focus of the event points to a rupture of the northeast in the northeast or dipping in the southwest. At the site of this earthquake, the Arab painting moves northward for Eurasia at a rate of $26 \mathrm{~mm}$ per year. The two teams converge along the north-western plateau in the general state of this earthquake, raising the Zagros Mountains in Iran. The location of the event and the shallow level of the Northeast are consistent with the solution of the coordination mechanism with the rupture of the relevant structure in this area [2].

Over the past century, the area located $250 \mathrm{~km}$ from the epicentre of the earthquake on November 12, 2017 subject to 4 other M6 earthquakes. The last of these crises was the earthquake M 6.1 away100 km south of the earthquake that happened on 1967. In the late 1950s and early 1960s, a series of earthquakes occurred 6.0-6.7 meters along the plate boundaries about $200 \mathrm{~km}$ southeast of the earthquake today. In November 2013, two earthquakes occurred at M 5.6 and 5.8, $60 \mathrm{~km}$ south of the November 2017 event. It is not known that they caused significant damage or deaths. An earthquake measuring 7.4 degrees in June 1990, 400 kilometres north-east of the November 12, 
2017 incident, killed 40,000 to 50,000 people and wounded more than 60,000, displacing more than 600,000 people in the region. Rasht - Caspian - cells of Iran.

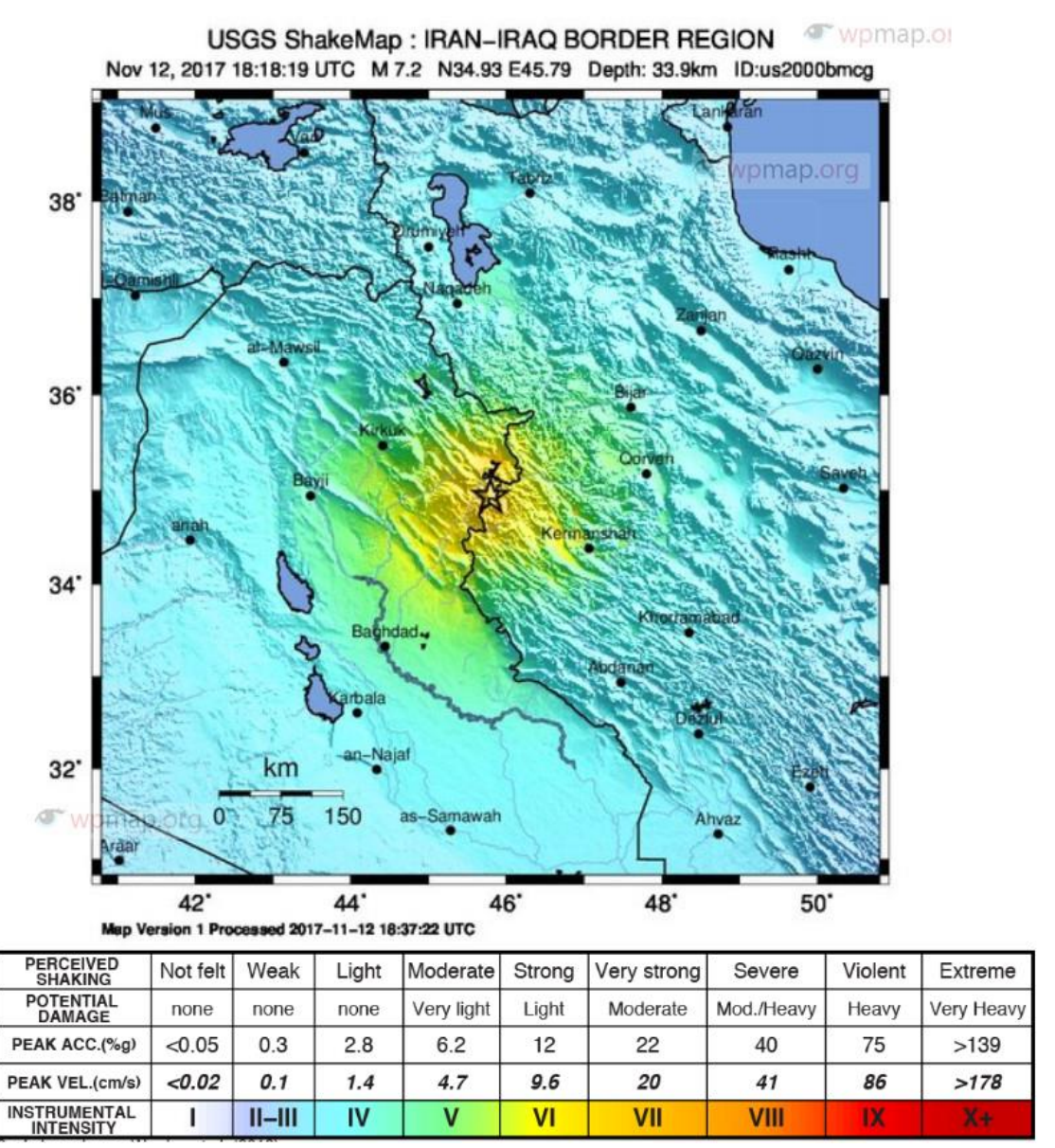

Fig. 1: The location and magnitude of earthquake [2].

As mentioned previously and due to the geographic of Iraq, most of the reservoirs and dams were built in the northern region. And because of recent earthquakes which hit the reign for various reasons, including the nature of the region and its proximity to the Iranian plate and the plate of Turkey, as a result of economic activity (oil extraction) and (Iranian nuclear reactors), the climate in the Middle East in general has often led to drought, leading to the construction of high-rise dams (such as the Eliseo dam in Turkey and other dams in Iran) [3]. All or some of these reasons lead to seismic activity in the area, some of which led to some obvious damage to the safety of the dams in Iraq, including the dam of Derbandikhan, which was clearly damaged by the earthquake of November 12, 2017 and $\mathrm{Mw}$ of 7.4, who followed us to study the causes and consequences of these tremors on the safety of dams, including Hashazini dam (the Iraqi government spent about 3,432 ID million) [4], which is the subject of our study.

The significant problem in the structural performance depending on Earthquake Engineering which is estimating the structural performance under the effect of seismic loads, particularly the estimating of the average annual ratio that exceeding a specific structural demand level (for example, maximum peak drift ratio $\square \square \max$ ) or a particular the capacity of limit-state (for example, instability of global dynamic). The most promising way to meet these requirements is the Incremental Dynamic Analysis (IDA), which includes a nonlinear dynamic analysis of the structural model in a set of ground motion registers, each measured at multiple intensity levels designed to force the structure on all flexibility to the ultimate global dynamic instability [5].

In addition to that, limit-states (for example, direct Occupancy or preventing Collapse) could be identified and summarized on each IDA curve for producing the exceeding probability for a given threshold given the IM level. 
The behavior of reinforced concrete structures under the effect of ground motions has always been a subject of investigation, especially in seismic regions. The final results must be in a proper format to be properly combined with traditional risk curve for calculating the thresholds for the country limit or specific request.

\section{Methodology}

IDA is a marginal analysis of seismic geometry to estimate a more comprehensive structural performance, elastic to nonlinear inelastic and finally to collapse. IDA includes the implementation of a series of dynamic nonlinear analyzes of a structural model under one or more ground movements, each measured at multiple levels of seismic density. The results are presented in terms of IDA curves for IM density measurement, which represent the measurement factor in the record, against DM or engineering demand parameter EDP, which characterize the response of the structural model. The instant messaging is usually selected as Earth peak ground Acceleration (PGA), Peak Speed in Earth, and 5\% damping ratio. DM can be any structural response quantity, and choose the appropriate DM depends on the application and structure itself. The seismic capacity of the structure can be determined and its specific conditions determined based on IDA curves[7]. Incremental dynamic analysis includes gradual every ground movement in a set of until get failure (collapse) or exceeding other level of performance of the structure.

The study of IDA is nowadays become a wide applicable and multi-function method because:

1. Understanding of demands or response range against potential ground movement levels record.

2. Improve the understanding of the implications of structural due to many ground movement levels.

3. Improve the understanding of the nature changes in the response of structure with increasing of ground motion intensity such as changes in (peak deformation, stiffness onset and degradation of strength's magnitudes and patterns).

4. Provide an estimating for the capacity of dynamic global structural system.

IDA is applied into performance-based earthquake engineering to find the expected structural response, damage, and financial loss under earthquake. According to IDA curve, the relationship between drift ratio and ground motions can be determined. Then, this relationship is utilized to determine performance level of a structure. This relationship also shows a range of behavior with large variation from each record.

A suitable set of ground motion records are needed to conduct IDA. Few parameters, such as event magnitude PGA, distance, and soil type, must be considered in selection of ground motions. For set of ground motions, most codes recommended a minimum of three or seven sets of ground motions.

Many researchers try to reduce the required recording data to represented the earthquake loss estimation curves (Katsanos and Vamvatsikos, 2017) was employed the equivalent single degree of freedom system (ESDOF) and Yield Frequency Spectra (YFS). While (Azarbakht and Dolšek, 2007) was used multi-degree-of-freedom (MDOF) model and nonlinear dynamic analysis of single-degree-of-freedom (SDOF) model [15-16]. In this paper will use the median of the available data in addition to $16 \%, 84 \%$ of the median data to give an indication very near to what happened in the reality.

The amount of structural response useful for estimating dynamic structural analyzes is the possibility of exceeding the maximum displacement as a function of ground motion intensity (often determined by spectral acceleration, Sa, in some specified period).

In most of the work of this type, the drift function is found in a gradual gradient of motion (for example, using the Incremental Dynamic Analysis (IDA)) until the Earth movement exceeds the recommended values for the Eurocode of the structure. These values are 0.025 for ultimate limit state ULS and 0.008 for service limit state SLS.

\section{General information on the Hashazini dam}

Hashazini dam is a concrete gravity dam with height of 12.00 height over the river bottom and $115.00 \mathrm{~m}$ the length of crest (3.00m wide). It is a small dam in the Region of Iraqi Kurdistan (North of Iraq) located in Sulaymaniyah. Sulaymaniyah is an Iraqi city located in the northeast of Iraq on the Iraqi-Iranian border and affiliated with the Kurdistan region. Sulaymaniyah governorate is located at an altitude of 2895 feet above sea level. the location of Hashazini (Or Hashazeny) dam is illustrated in figure 2. 


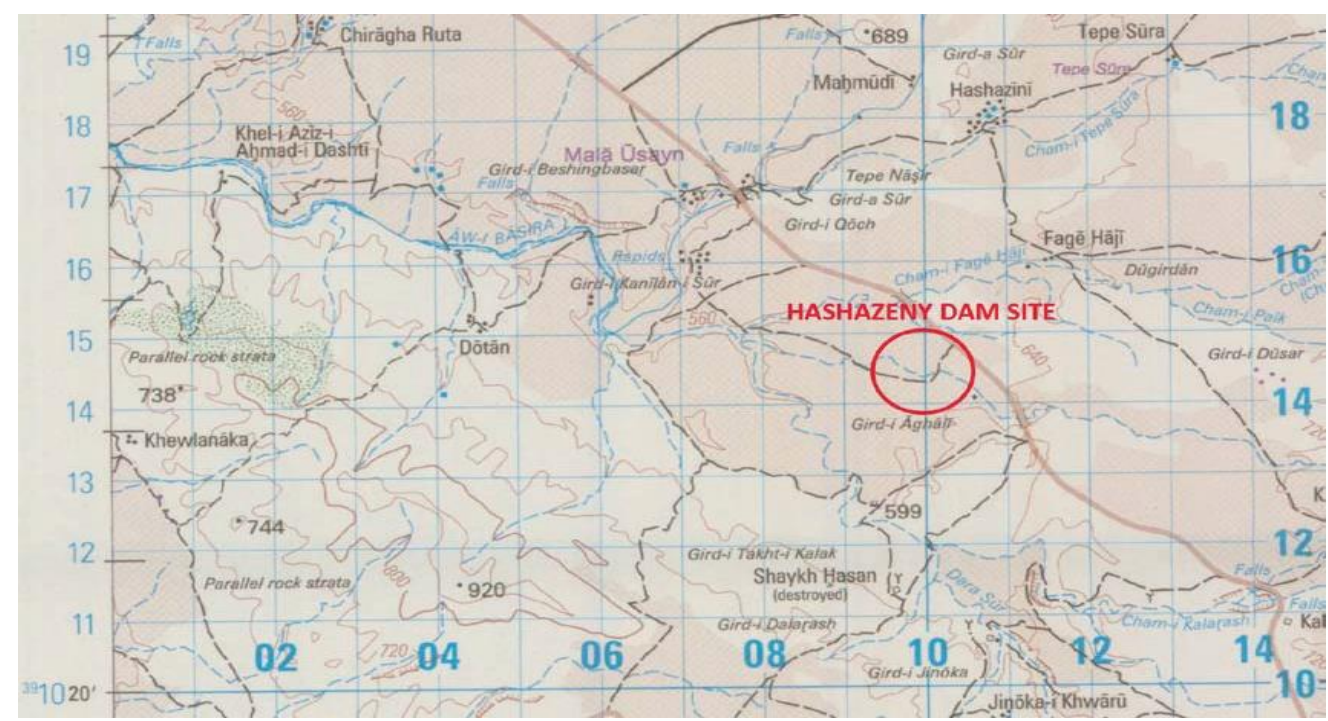

Fig. 2: Location of Hashazini dam.

The mountainous nature of the province prevails as it grows towards the eastern border with Iran. It is located 140 kilometres away from the province of Kirkuk, and the population is currently 656,000. And according to (USGS, 2017) this region subject to a series of earthquake and the maximum magnitude was M7.3 [1, 2, 4]. Figure 5 demonstrates the Hashazini dam layout.

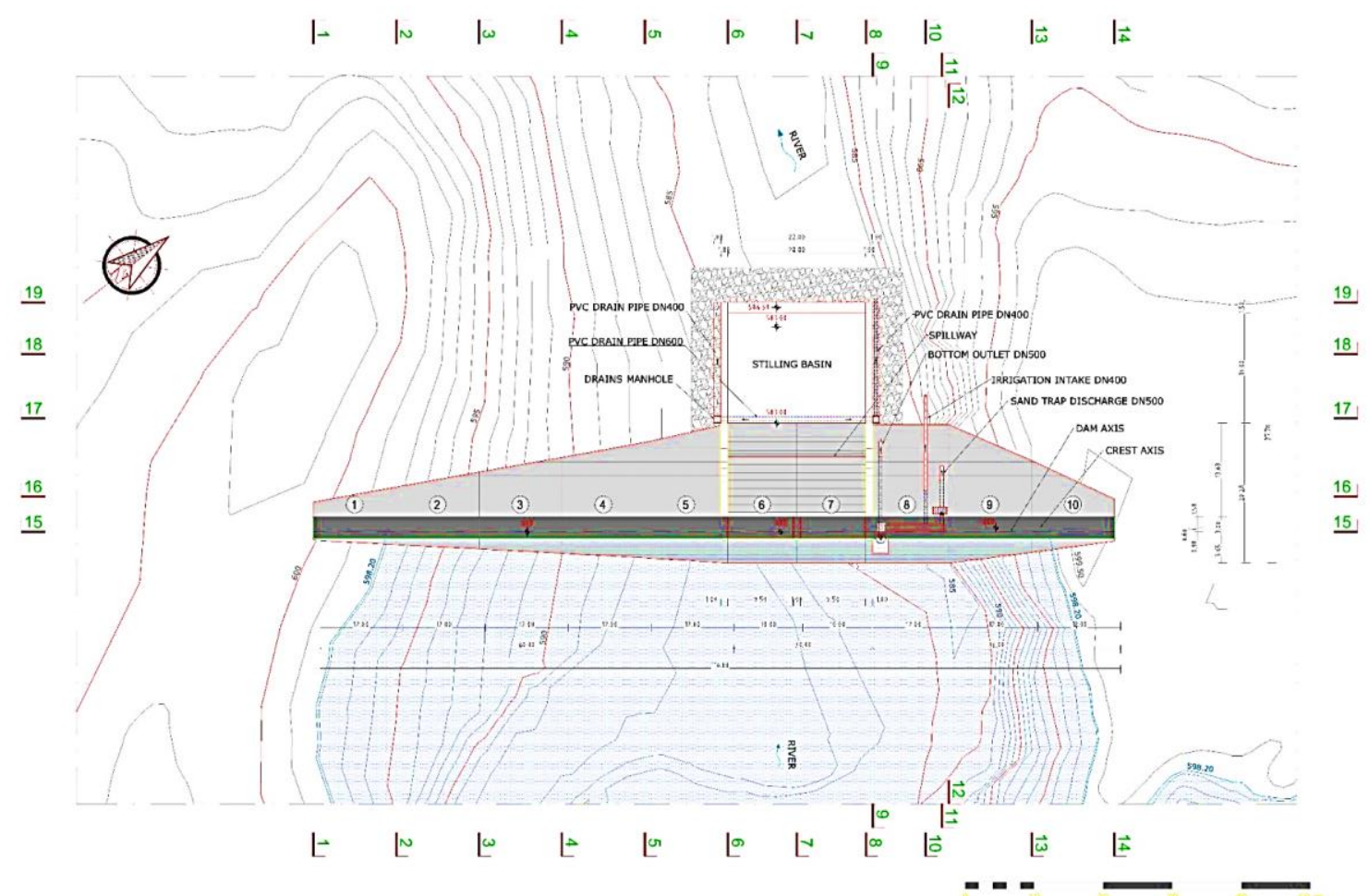

Fig. 3: The Hashazini dam layout.

The cross- section of Hashazini dam as demonstrated in Figure 4 which drawing by AUTOCAD and ANSYS simulation programme. 


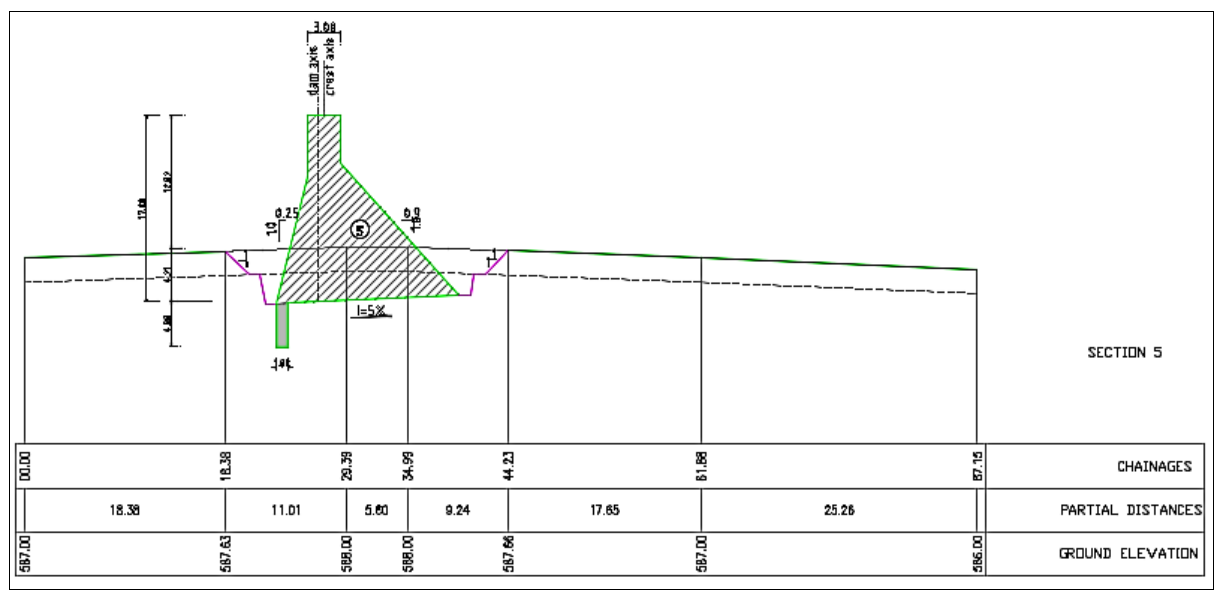

Fig. 4: Section of Hashazini dam.

\section{Result and Discussion}

The modelling of Hashazini dam is performed by ansys software as shown in figure 5 .

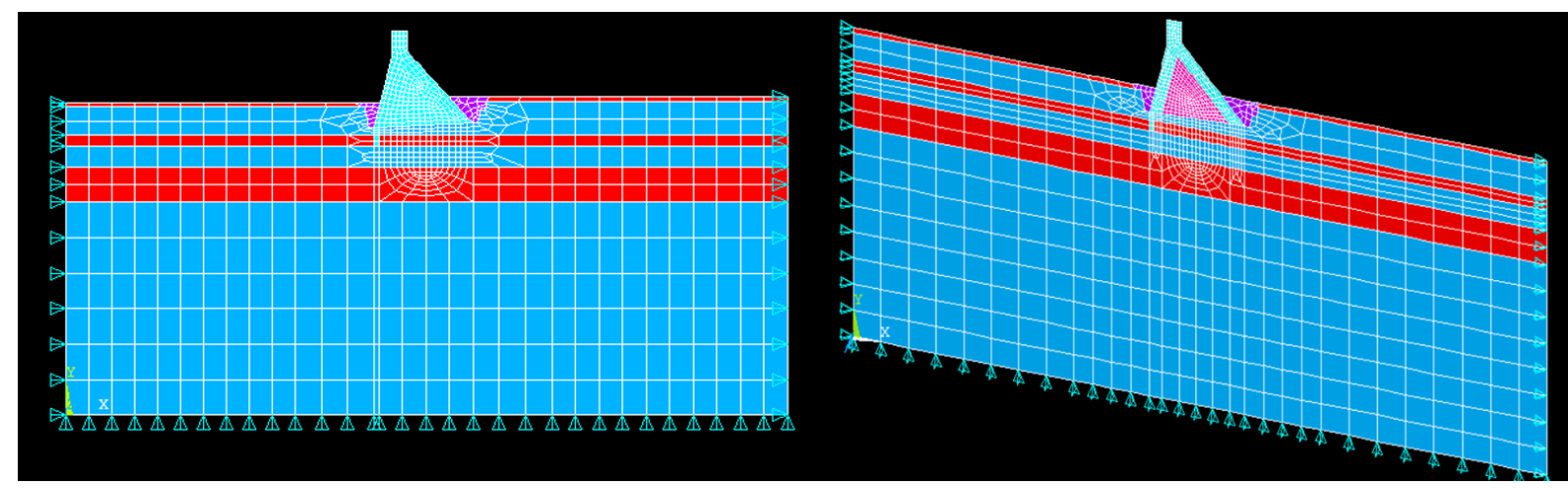

Fig. 5: Modeling of Hashazini dam.

\section{IDA Analysis}

A seven sets of ground motions were used in this study, as shown in table 1, these ground motions was chosen from Pacific Earthquake Engineering Research Center (PEER) data base for different earthquake in different places.

Table 1: Parameters of the selected ground motion.

\begin{tabular}{|c|l|c|l|c|c|}
\hline No. & Earthquake & Date & Recording station & Magnitude & PGA \\
\hline 1 & Imperiall Valey & 1979 & USGS STATION 5115 & 6.5 & 0.3152 \\
\hline 2 & Friuli & 1976 & TOLMEZZO(000) & 6.5 & 0.3513 \\
\hline 3 & Hollister & 1961 & USGS STATION 1028 & 5.9 & 0.1948 \\
\hline 4 & Trinidad & 1983 & 090 CDMG STATION 1498 & 3.2 & 0.1936 \\
\hline 5 & Kocaeli & 1999 & YARIMCA(KOERI330) & 7.6 & 0.349 \\
\hline 6 & Lama Pierta & 1989 & 090 CDMG STATION 47381 & 6.9 & 0.3674 \\
\hline 7 & Northridge & 1994 & 090 CDMG STATION 24278 & 6.7 & 0.5683 \\
\hline
\end{tabular}


Every structure subject an earthquake should take in the consideration the magnitude and the peak of ground acceleration during designing this building to prevent or mitigate significant damages of the structure and loses of life that could be resulting from these damages. And all these considerations will be more important it related with an infrastructure like a dam. Therefore, in this paper the IDA curve is developed by take many estimations such as $16 \%$ of IDA, median and $84 \%$ of IDA which has been gotten by found multiplied the median by $16 \%$ and $84 \%$ respectively. And the results is recorded in table 2. From the results in table 2. The elastic response spectra were incrementally developed from $0.1 \mathrm{~g}$ to 2.2 g every $0.3 \mathrm{~g}$.

Table 2: Results of drift for each ground motion.

\begin{tabular}{|r|c|c|c|c|c|c|c|c|c|c|}
\hline & \multicolumn{10}{|c|}{ Drift ratio } \\
\cline { 2 - 12 } PGA & 1_IV & 2_Friuli & 3_Hollister & 4_Trinidad & 5_Kocaeli & 6_LP & 7_Northrige & IDA 16\% & Median & IDA 84\% \\
\hline 0 & 0.000 & 0.000 & 0.000 & 0.000 & 0.000 & 0.000 & 0.000 & 0.000 & 0.000 & 0.000 \\
\hline 0.1 & 0.002 & 0.001 & 0.002 & 0.001 & 0.003 & 0.002 & 0.003 & 0.001 & 0.002 & 0.002 \\
\hline 0.4 & 0.007 & 0.006 & 0.006 & 0.002 & 0.011 & 0.011 & 0.010 & 0.005 & 0.007 & 0.011 \\
\hline 0.7 & 0.015 & 0.010 & 0.011 & 0.004 & 0.022 & 0.023 & 0.017 & 0.009 & 0.013 & 0.022 \\
\hline 1 & 0.026 & 0.015 & 0.021 & 0.006 & 0.037 & 0.041 & 0.023 & 0.013 & 0.022 & 0.038 \\
\hline 1.3 & 0.030 & 0.021 & 0.028 & 0.009 & 0.064 & 0.063 & 0.030 & 0.018 & 0.029 & 0.063 \\
\hline 1.6 & 0.033 & 0.026 & 0.034 & 0.011 & 0.101 & 0.080 & 0.040 & 0.023 & 0.033 & 0.084 \\
\hline 1.9 & 0.037 & 0.031 & 0.039 & 0.012 & 0.167 & 0.094 & 0.050 & 0.027 & 0.038 & 0.109 \\
\hline 2.2 & 0.047 & 0.035 & 0.044 & 0.014 & 0.215 & 0.110 & 0.065 & 0.031 & 0.045 & 0.131 \\
\hline
\end{tabular}

It is easy to find and indicate the relationship between drift and PGA for all earthquakes that found in table 1. As shown in figure 8 . And figure 9 median of the available data in addition to $16 \%, 84 \%$ of the median data to give an indication very near to what happened in the reality.

The important result that obtained from the incremental dynamic analysis of the dam is the chart that demonstrate the relationship between the peak ground acceleration (PGA) of each earthquake in the selected steps between 0.1 and 2.1 with the maximum drift ratio that obtained from these earthquakes as shown in figure 6.

Figure 10. shows the relationship between PGA and drift.

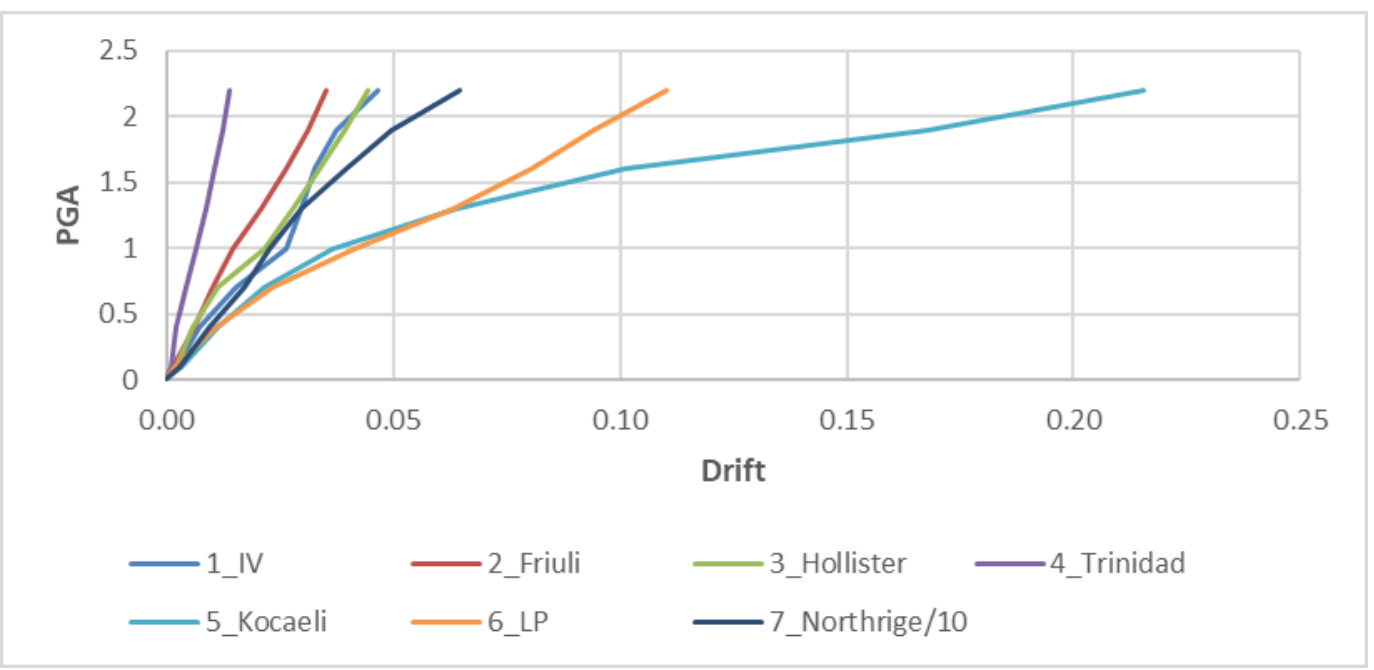

Fig. 6: IDA curve for selected ground motion. 
Other important charts are the chart that compare the results from IDA with SLS and ULS and also with their related results that obtained from $16 \%$, median and $84 \%$ as shown in 7 and the chart which compare the peak ground acceleration with the maximum drift as shown in figure 8.

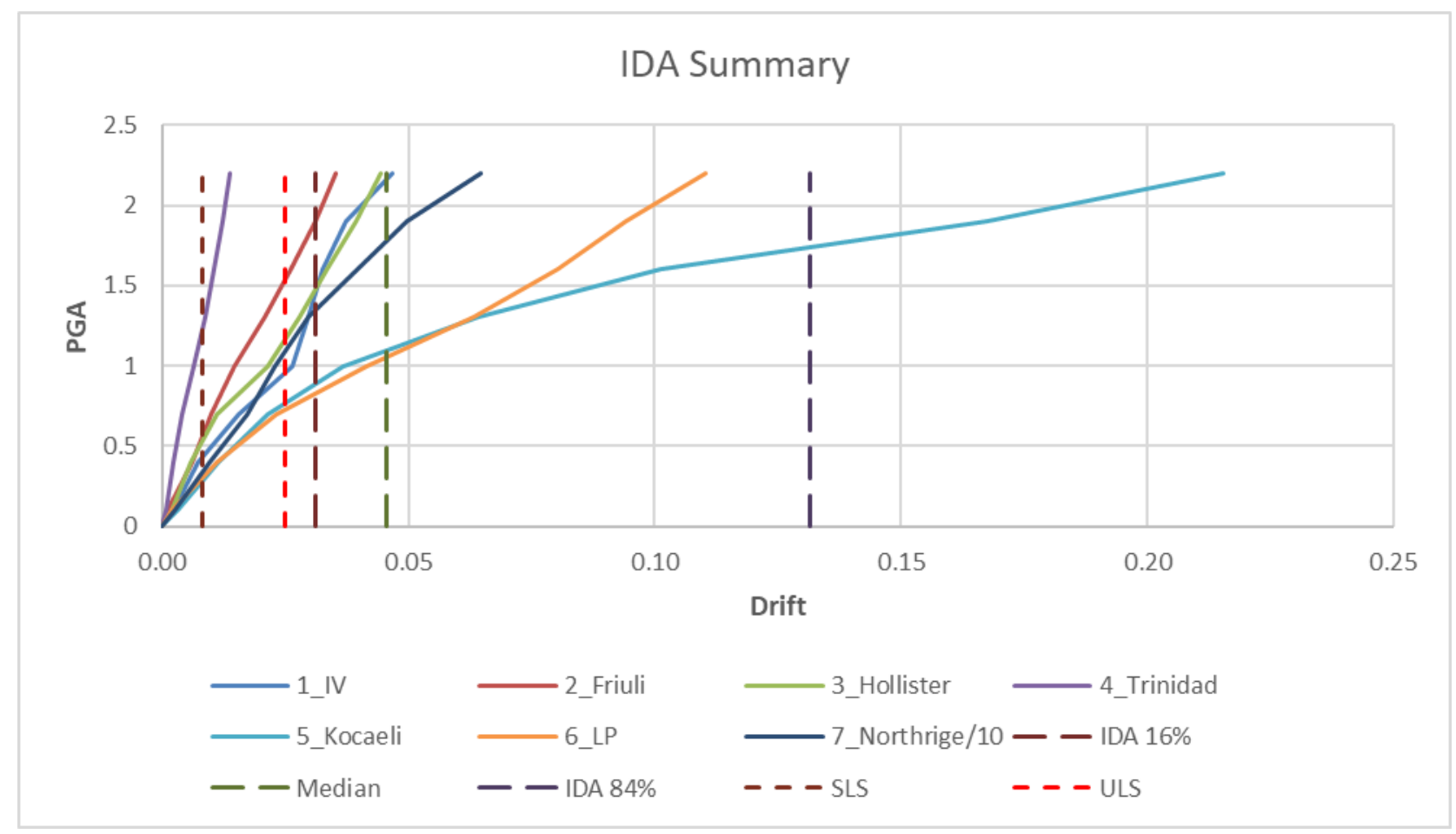

Fig. 7: Comparison of the IDA results with SLS, ULS, $16 \%$, median and $84 \%$.

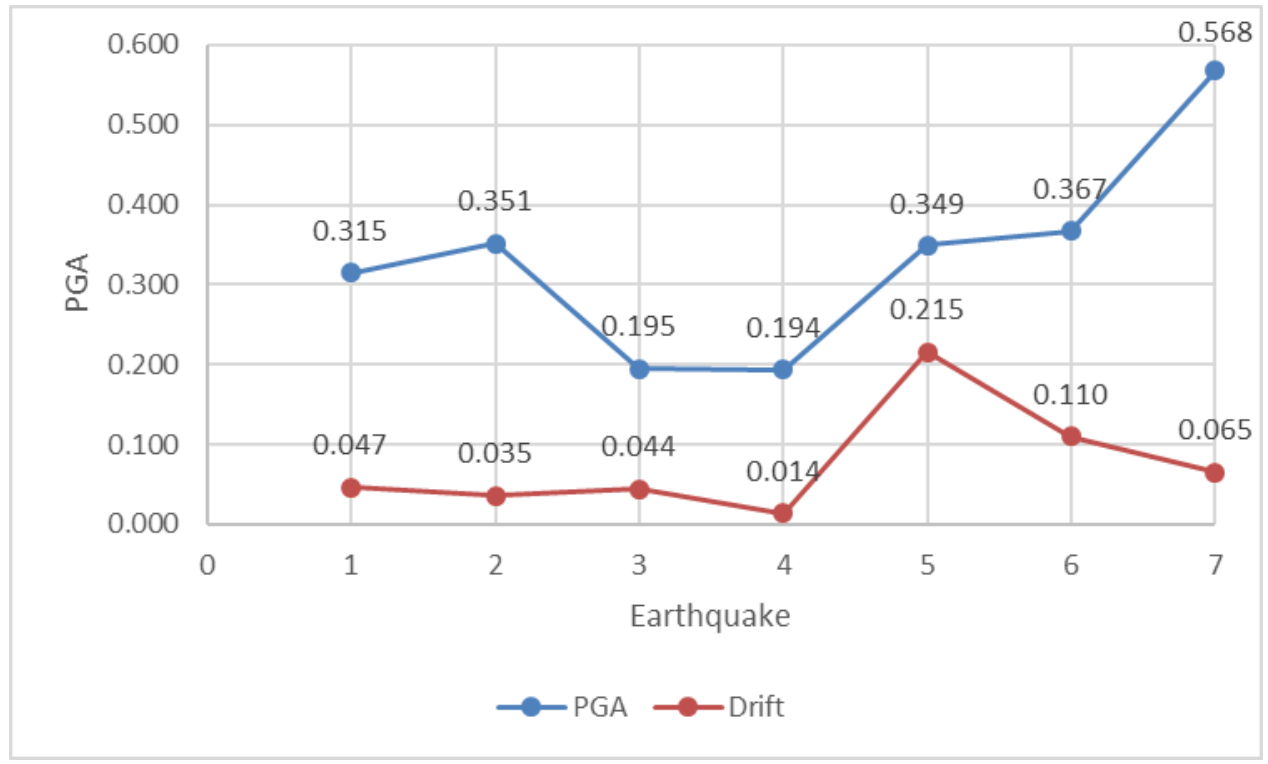

Fig. 8: PGA with maximum drift for each GM. 


\section{Conclusion}

Incremental dynamic analysis IDA was developed and presented in this paper in order to evaluate evaluate the nonlinear seismic performance of the concrete gravity dam. The selected dam was Hashazini in Sulaymaniyah, the city in the north of Iraq. The parameter that used in this report for the evaluation process is maximum drift ratio according to Eurocode 8. To limit states are used for comparison, Service limit SLS and ultimate limit ULS. It could be concluded that the dam in most cases of selected ground motion could be able to transmit the seismic loads, in significant earthquake such as Kocaeli the expected drift ratio is exceeding the allowed SLS that recommended by Eurocode.

\section{References}

[1] Fao.org. (2019). Iraq at a glance |FAO in Iraq | Food and Agriculture Organization of the United Nations [Online]. Available at: http://www.fao.org/iraq/fao-in-iraq/iraq-at-a-glance/en/

[2] USGS (2017). M 7.3-29 km South of Halabjah, Iraq [Online]. Earthquake.usgs.gov. Available at: https://earthquake.usgs.gov/earthquakes/eventpage/us2000bmcg/executive

[3] H. Hameed. "Article Eliseo Turkish Dam and its Impact on the Water Contained the Tigris River in Iraq," Journal of Research Diyala humanity, vol. 68, pp. 1-24, 2015.

[4] World Bank Group, (2017). KURDISTAN REGIONAL GOVERNMENT ECONOMIC REFORM IMPLEMENTATION PROGRESS. [Online] Available at: http://www.mop.gov.krd/resources/MoP\%20Files/PDF\%20Files/ECONOMIC\%20REFORM\%20IMPLEMENTATIO N\%20REPORT.pdf

[5] D. Vamvatsikos and C. A. Cornell. "The incremental dynamic analysis and its application to performance-based earthquake engineering," in Proceedings of the 12th European conference on earthquake engineering, 2002, vol. 40.

[6] N. N. Pujari, T. K. Mandal, S. Ghosh and S. Lala, "Optimisation of IDA-based fragility curves. In Safety, Reliab. Risk Life-Cycle Perform," Struct. Infrastructures-Proc. 11th Int. Conf. Struct. Saf. Reliab, ICOSSAR 2013, no. Dm, pp. 4435-4440, 2013.

[7] D. Vamvatsikos and C. A. Cornell, "Incremental dynamic analysis. Earthquake Engineering \& Structural Dynamics", Department of Civil and Environmental Engineering; Stanford University, 31(3), pp. 491-514, 2002.

[8] S. N. A. Saruddin and F. M. Nazri, "Fragility curves for low-and mid-rise buildings in Malaysia," The 5th International Conference of Euro Asia Civil Engineering Forum (EACEF-5), Penang, Malaysia, 125, pp.873-878, 2015.

[9] K. Porter, "A Beginner's guide to fragility, vulnerability, and risk," University of Colorado Boulder. Boulder and SPA Risk LLC, Denver CO USA, September 2017.

[10] A. Gkimprixis, "Seismic Analytical Fragility Functions for Reinforced Concrete Buildings, capturing Uncertainties," Doctoral dissertation, Aristotle University of Thessaloniki. Thessaloniki, 2015.

[11] M.S. Kirçil and Z. Polat, "Fragility analysis of mid-rise R/C frame buildings," Engineering Structures, vol. 28, no. 9, pp. 1335-1345, 2006.

[12] J. W. Baker "Efficient analytical fragility function fitting using dynamic structural analysis," Earthquake Spectra, vol. 31, no. 1, pp. 579-599, 2015.

[13] K. A. Korkmaz, "Evaluation of seismic fragility analyses," The 14th world Conference on Earthquake Engineering, Beijing, China, 2008.

[14] D. Lu, X. H. Yu and M. M. Jia "Analytical formulations of fragility functions with applications to probabilistic seismic risk analysis," in Proceedings of the 15th World Conference on Earthquake Engineering, Lisbon, Portugal 2012.

[15] E. I. Katsanos and D. Vamvatsikos, "Yield frequency spectra and seismic design of code-compatible RC structures: an illustrative example," Earthquake Engineering \& Structural Dynamics, vol. 46, no. 11, pp. 1727-1745, 2017.

[16] A. Azarbakht and M. Dolšek, "Prediction of the median IDA curve by employing a limited number of ground motion records," Earthquake Engineering \& Structural Dynamics, vol. 36, no. 15, pp. 2401-2421, 2007.

[17] E. M. Bretas, "Desenvolvimento de um modelo de elementos discretos para o estudo de barragens gravidade em alvenaria," 2012.

[18] J. W. Mauk, Y. S. Kim and H. J. Kim, "Seismic Performance of Reinforced Concrete Frames Infilled by Masonry Walls with Different Heights," World Academy of Science, Engineering and Technology, International Journal of Civil, Environmental, Structural, Construction and Architectural Engineering, vol. 9, no. 2, pp. 158-161, 2015. 